\title{
Yeşil Tedarik Zinciri Uygulamalarına İlişkin Gaziantep Organize Sanayi Bölgesinde Bir Araştırma ${ }^{1}$
}

\author{
İbrahim AKBEN \\ Dr. Öğr. Üyesi, Hasan Kalyoncu Üniversitesi \\ Uluslararası Ticaret ve Lojistik Bölümü \\ ibrahim.akben@hku.edu.tr \\ Orcid ID: https://orcid.org/0000-0003-3268-0242
}

\begin{abstract}
Öz
Günümüzde, doğal kaynakların tükenme noktasına gelmesi, tüketicilerin çevresel konularda farkındalıklarının oluşması ve satın alma davranışlarının değişmesi, üretim faaliyetlerinin daha çevreci bir şekilde yapılmalarını zorunlu hale getirmiştir. İşletmeler, yeşil uygulamalarla çevreye verdikleri zararı en aza indirgeyerek veya tamamen yok ederek, hem sosyal sorumluluklarını yerine getirme hem de çevreci bir imaj oluşturma çabaları içerisindedirler. Bu önemli çevreci faaliyetlerden birisi de yeşil tedarik zinciri uygulamalarıdır. Yeşil tedarik zinciri; işletmelerin, neredeyse bütün faaliyetlerinde çevreci bir yaklaşım belirlemeleri olarak tanımlanabilir.

Bu çalışmanın amacı, yeşil tedarik zinciri konusunda Gaziantep işletmelerinin sahip olduğu farkındalığı belirlemek ve sahip oldukları çevre bilinci ile yeşil lojistiğin önemli uygulamalarından biri olan tersine lojistik konusunda bir araştırma gerçekleştirmektir. Bu amaçla çalışmada bir anket formu aracılığıyla 112 firmadan veriler toplanmış ve uygun istatistiki teknikler kullanılarak sonuçlara ulaşmaya çalışılmıştır. Çalışmanın sonucunda işletmelerin çevresel duyarlılığının, tersine lojistik uygulamaları üzerinde pozitif etkiye sahip olduğu belirlenmiştir.
\end{abstract}

Anahtar Kelimeler: Çevresel Duyarlılık, Tersine Lojistik, Yeşil Tedarik Zinciri.

${ }^{1}$ Makale Geliş/Kabul Tarihi: 04.10.2020 / 15.03.2020

Künye Bilgisi: Akben, İ. (2021). Yeşil tedarik zinciri uygulamalarına ilişkin Gaziantep organize sanayi bölgesinde bir araştırma. Kahramanmaraşs Sütçü İmam Üniversitesi Sosyal Bilimler Dergisi, 18(1), 456-477. DOI: 10.33437/ksusbd.821261 


\title{
Green Supply Chain Applications A Research In Gaziantep Organized Industrial Zone
}

\begin{abstract}
Today, the depletion of natural resources, the awareness of consumers on environmental issues and the change in purchasing behavior have made production activities more environmentally friendly. Companies are in an effort to fulfill their social responsibilities and create an environmentally friendly image by minimizing or eliminating the damage they cause to the environment with green practices. One of these important environmental activities is green supply chain practices. Green supply chain can be defined as the enterprises' determination of an environmentalist approach in almost all their activities.

The purpose of this study is to determine the awareness of Gaziantep firms on green supply chain and to conduct a research on reverse logistics, which is one of the important applications of green logistics for environmental awareness. For this purpose, data from 112 firms were collected through a questionnaire in the study and the results were tried to be reached by using appropriate statistical techniques. As a result of the study, it was determined that the environmental awareness of companies has a positive effect on reverse logistics applications.
\end{abstract}

Keywords: Environmental Awareness, Reverse Logistics, Green Supply Chain.

\section{GíRIŞ}

Günümüzde işletmeler, yeşil uygulamalarla çevreye verdikleri zararı en aza indirgeyerek veya tamamen yok ederek, hem sosyal sorumluluklarını yerine getirme hem de çevreci bir imaj oluşturma çabaları içerisindedirler. Tüketicilerin giderek bilinçlendiği günümüz şartlarında, işletmeler oluşturdukları bu olumlu imaj ile birlikte yeşil tedarik zinciri uygulamalarını da gerçek anlamda gerçekleştirdiklerinde operasyonel maliyetlerinde orta ve uzun vadede ciddi anlamda bir düşüş sağlayabilmektedirler. Buna ek olarak işletmeler, kaliteli mal ve hizmet üretimi de yaptıklarında ulusal ve uluslararası iş ortamında önemli bir rekabet avantaji elde etmektedirler.

İşletmelerin her türlü faaliyetlerinin çevresel sorunlara sebep olması, tüketicilerin çevre ile ilgili farkındalıklarının artmasına sebep olmuștur. Bunlarla ilişkili olarak, biyolojik, kimyasal ve fiziksel atıklarla doğanın kirletilmesi neticesinde insan hayatının olumsuz etkilenmesi ve gelecek nesillere daha yaşanılabilir çevre bırakabilme isteği, kirliliğe karşın önlemlerin alınmasını 
zorunlu kılmıştır (Yarlıkaş ve Can, 2019: 900).

Geleneksel bir tedarik zinciri yönetimi, çevresel negatif etkileri ve zincir üzerindeki paydaşların ihtiyaçlarını karşılayamama ve sürdürebilirliği sağlayamamaktadır (Koca ve Behdioğlu, 2020: 675). Bundan dolayı; katı düzenlemeler, artan sivil toplum örgütleri ve tüketici baskıları nedeniyle üreticilerin, çevresel kaygıları düzenli uygulamalarına ve stratejik planlama gündemlerine etkin bir şekilde entegre etmeleri gerekir. Çevresel kaygıları tedarik zinciri yönetimine entegre etmek, üreticilerin rekabet avantajı kazanması ve bu avantajı sürdürmesi için giderek daha önemli hale gelmiştir (Zhu vd., 2008: 261262).

Çevre bilincine sahip iş uygulamaları, hem araştırmacılar hem de uygulayıcılar tarafindan giderek daha fazla ilgi çekmeye devam etmektedir. Yeşil tedarik zinciri ile ilgili olarak son zamanlarda disiplinler arası araştırmalarla, bu konunun yönetim, mühendislik, fiziksel ve sosyal bilimlerin de bu sürece dâhil olmasıyla (Sarkis, 2003: 397) yeşil tedarik zinciri alanı birçok açıdan disiplinler arası önemli bir çalışma haline gelmiştir.

$\mathrm{Bu}$ çalışmanın amacı, yeşil tedarik zinciri konusunda işletmelerinin ne kadar farkındalığa sahip oldukları ve çevre bilinci ile yeşil lojistiğin önemli uygulamalarından biri olan tersine lojistik konusunda bir alan çalışması gerçekleştirmektir.

$\mathrm{Bu}$ amaçla çalışma; giriş bölümü, yeşil tedarik zinciri, yeşil tedarik zinciri uygulamaları, analiz ve bulguların yer aldığı alan çalışması ve sonuç bölümü olmak üzere toplam da beş bölüm olarak tasarlanmıştır.

\section{TEDARÍK ZINCİRI YÖNETIMI VE YEŞİL TEDARÍK ZİNCİRi KAVRAMI}

Tedarik zinciri, müşterilerinin ihtiyaçlarını karşılayabilmek için üretimi ve sunumu yapılacak mal, hizmet ve bilgilerin kaynağından nihai kullanıcılara kadar olan akışının planlanması, yönetilmesi gibi unsurları barındıran bir dizi faaliyetler olarak ifade edilebilir. Ayrıca tedarik zinciri konusunda literatürde birçok tanımlama yapılmıştır. Bu tanımlamalardan önemli bulunanlarına değinmek gerekirse; Tedarik zinciri konusunda önemli bir otorite olan Tedarik Zinciri Profesyonelleri Konseyi’nin tedarik zinciri yönetimi tanımlamasını: "Tedarik zinciri yönetimi satın alma, tedarik, dönüşüm ve tüm lojistik yönetimi faaliyetlerinde yer alan bütün operasyonların planlanması ve yönetimini içerir. Aynı zamanda kanal ortaklarıyla koordinasyon ve işbirliğini de içerir. Özünde, tedarik zinciri yönetimi, arz ve talep yönetimini şirket içinde ve şirketler arasında bütünleştirir” (CSCMP, 2008) şeklinde yapmıştır. 
Bowersox vd., (2002)'e göre ise tedarik zinciri yönetimi "Stratejik konumlamayı değerlendirmek ve işletmelerin verimliliğini artırmak için işbirliği yapan firmalardan oluşmaktadır. Tedarik zinciri operasyonları, bireysel firmalardaki işlevsel alanlara yayılmış, ticaret ortakları ve müşterileri örgütsel sınırlar arasında bağlayan yönetsel süreçleri gerektirir" şeklinde açıklamışlardır.

Diğer bir tanımlamaya göre tedarik zinciri; hammaddenin teminini sağlayan ve bu hammaddeleri yarı mamul ve son mamullere dönüştüren ve bu mamulleri son kullanıcıya ulaştıran, imalatçı ve dağıtıcı işletmelerden oluşan bir ağ olarak ifade edilebilir (Lee and Billington, 1992: 66).

Tedarik zincirlerinin yönetilmesinde, müşteri gereksinimlerini karşılayacak biçimde, malların doğru zamanda, doğru yerde, doğru miktarda var olması ve toplam maliyetinin azaltılması için yan sanayicilerin, imalat işletmelerinin, depoların ve satış yerlerinin etkili entegrasyonunu hedeflenmektedir (Büyüközkan ve Vardaloğlu, 2008: 4).

Şekil 1'de tedarik zincirinin genişletilmiş bir yapısı görülmektedir. Şekil' de tedarik zinciri yapısı incelendiğinde; üretimde kullanılan hammaddelerin kaynaklarından elde edilmesinden başlayıp son kullanıcı ile sona ermektedir. $\mathrm{Bu}$ zincir mamullerin tekrar kullanımı ya da geri dönüşümü de kapsamaktadır.

Genişletilmiş tedarik zincirinde planlama, mamul tasarımı, üretim, montaj, mamullerin hareketi, depolama ve dağıtım fonksiyonları yürütülmektedir. Ayrıca süreçler esnasında ortaya çıkan atıklar şekil üzerinde "W" ile ifade edilmektedir (Büyüközkan ve Vardaloğlu, 2008: 6).

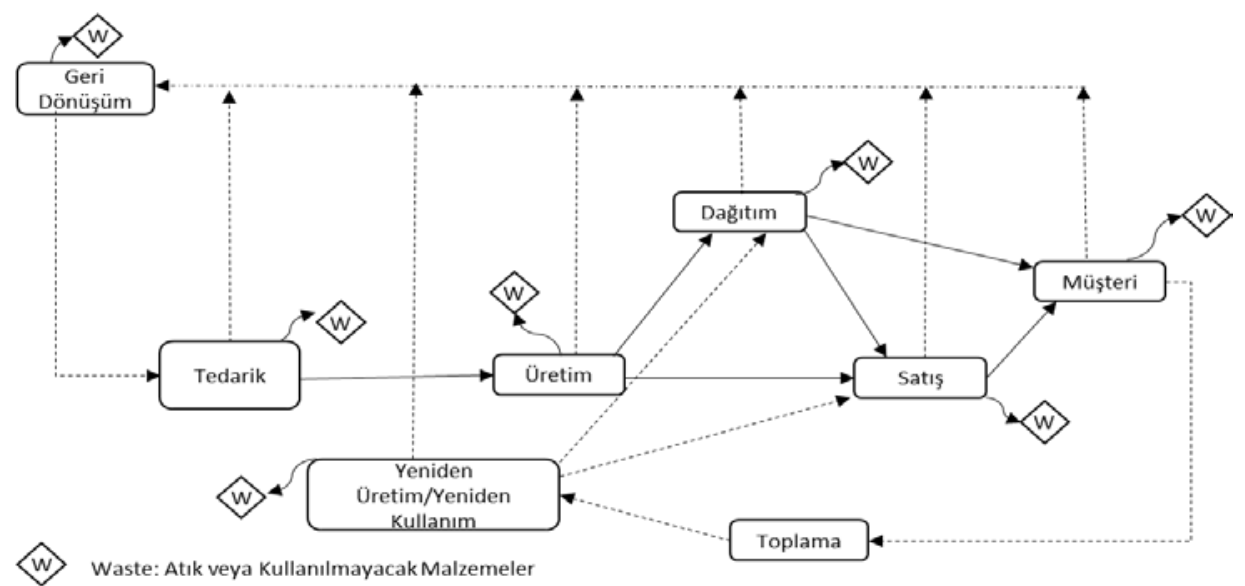

Şekil 1. Genişletilen Tedarik Zinciri Yapısı

Kaynak: Beamon (1999: 332-342). 
Burada tersine lojistik, ileriye doğru ve açık uçlu tedarik zincirini, sürece kattı̆̆ 1 yeniden kullanma, yeniden üretme ya da malzemelerin başka bir yarı mamule veya pazar değerine sahip başka mamullere dönüşümü işlemleriyle kapalı bir çevrim halini almaktadır. Burada temel gaye, enerji emisyonları, kimyasal maddeler, katı atıklar gibi her türlü atıkların çevreye olan negatif etkilerinden tedarik zinciri sürecini arındırmaktır (Büyüközkan ve Vardaloğlu, 2008: 5). Bu geleneksel tedarik zinciri, çevresel kaygıların baş göstermesi ve belli otoritelerin ve tüketicilerin baskılarıyla çevreci bir hale bürünerek, yeşil tedarik zinciri adını verdiğimiz bir hal almıştır. Yeşil tedarik zinciri yönetimi, hem çevre yönetimi hem de tedarik zinciri yönetimi ile birlikte ele alınmaktadır. Tedarik zinciri yönetimine "yeşil" bileşenin eklenmesi, tedarik zinciri yönetimi ile doğal çevre arasındaki etkiyi ve ilişkileri temsil etmektedir (Srivastava, 2007: 54). Tedarik zincirinde olduğu gibi yeşil tedarik zinciri için geniş ve bütüncül bir tanımı bulunmamakla beraber, literatürde bazı tanımlamalar yapılmıştır. Yeşil tedarik zincirleri, tedarik zinciri unsurlarını çevre yönetimi ile entegre edilmesinden oluşmaktadır (Sarkis and Dou, 2018). (Sarkis vd., 2011) 'e göre; Yeşil tedarik zinciri, tersine lojistik de dahil olmak üzere sürdürülebilir tedarik zinciri yönetiminin örgütler arası uygulamalarına çevresel endişeleri entegre etmek olarak tanımlamışlardır.

Yeşil tedarik zinciri, ürünün geri dönüşümü ya da kullanımı zararlı maddelerin azaltılması, kaynak tasarrufu, yeşil tasarım gibi ürünün bütün yaşamı süresince, çevresel etkilerini en aza indirmeyi hedefleyen hareketleri içeresinde barındıran standart bir tedarik zincirinin genişletilmiş halidir (Güzel ve Demirdöğen, 2015: 46).

Yeşil tedarik zinciri, kendisine atfedilen çevreci görevleri yerine getirebilmek adına bazı uygulamalardan yararlanmaktadır.

\section{ÇEVRESEL DUYARLILIK VE YEŞIL TEDARIK ZINCİII UYGULAMALARI}

Günümüzde işletmeler için lojistik pazar, mamul ve hizmetlerin sunulmasında rekabet avantajı sağlamak anahtar bir rol oynamaktadır. Artan çevresel baskılar neticesinde son kullanıcıların çevreci ürün, yeşil ürün, yeşil süreçler gibi değerlere olan ilgisi artmaktadır (Akben ve Demirer, 2020: 17). Çevresel duyarlılığa bağlı olarak işletmelerin yeşil tedarik zinciri uygulamaları bir işletmenin üretim ve örgüt stratejilerini de kapsayan geniş çaplı uygulamalar olarak kabul edilip, tüm çalışanlar tarafından benimsenerek işletmenin bütün birimlerince desteklenmelidir (Sarkis, 2001: 668). Örneğin, ISO 14001 çevre yönetim sisteminin uygulanması sadece işletmenin bir biriminin çalışanlarının değil, tepe yönetiminden en alt kademeye kadar bütün çalışanların bu sürece katılımıyla gerçekleşmektedir. 
İşletmelerin yeşil faaliyetlerini izleyen ve sertifikalayan kurumlar olduğu gibi tüketiciler de işletmelerin bu faaliyetlerini önemsemektedir.

İşletmelerin faaliyetlerinde bütün birimleri ile birlikte kullanabilecekleri yeşil tedarik zinciri ile ilgili bazı çevreci (yeşil) uygulamalar mevcuttur. Bu çevreci uygulamalar; yeşil satın alma, yeşil üretim, yeşil dağıtım, yeşil paketleme ve tersine lojistik uygulamaları olarak sıralanabilir.

Şekil 2'de yeşil tedarik zinciri yönetiminde kullanılan, yeşil uygulamalar şematize edilmiştir.

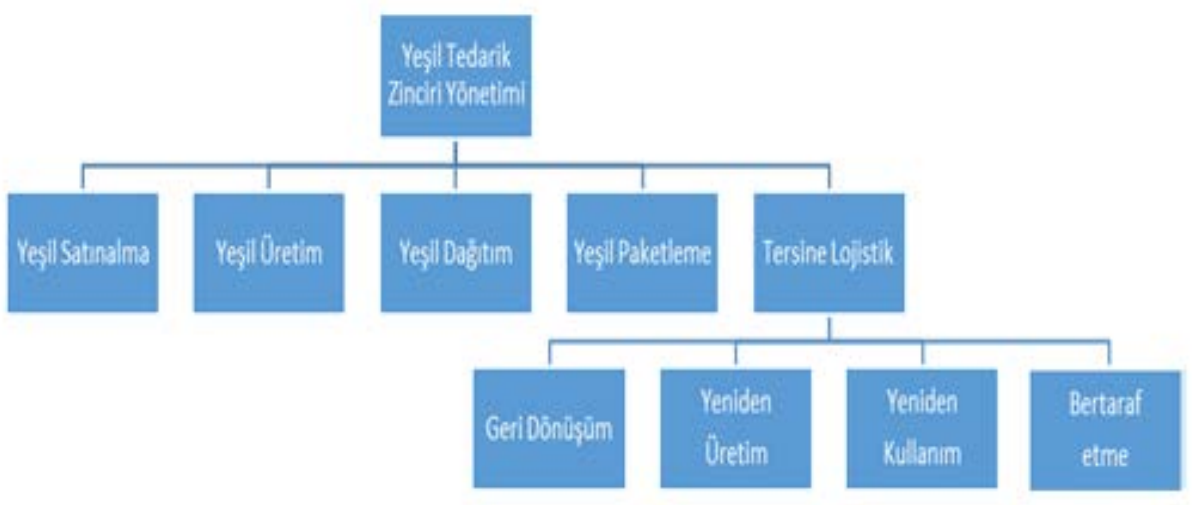

Şekil 2. Yeşil tedarik zinciri yönetimindeki yeşil uygulamalar

Kaynak: Büyüközkan ve Vardaloğlu (2008: 6).

\section{Yeşil satın alma}

Yeşil satın alma, çevresel etkilerin ve enerji tüketiminin fiyat, kalite ve teslimat gibi diğer konularla yan yana değerlendirildiği ürün ve hizmetler olarak tanımlanmaktadır. Tüm ürünler, hammaddeden üretim sürecine, nakliyeye ve atık yönetimine kadar çevreye son derece etkilerler (Hart vd., 2010). Ek olarak, çevre dostu olmayan davranışlardan kaçınmak, çevresel amaçları gerçekleştirmek için tedarikçilerle işbirliği yapmak, tedarikçileri denetlemek, tedarikçilerin iç çevre yönetim sistemini denetlemek ve çevresel performansı tedarikçilere entegre etmek (Sarkis and Dou, 2018) olarak ifade edilebilir.

\section{Yeşil üretim}

Yeşil üretim, üretim süreçlerinde doğru, çevreci teknikler ve malzemeler kullanarak çevreye verilen zararın azaltılması olarak tanımlanabilir. Yeşil üretim 
konusunda imalat endüstrisinin asıl endişesi şu şekilde sıralanabilir (Kaur vd., 2018):

- Yeşil enerji; rüzgar enerjisi, güneş enerjisi, sıkıştırılmış doğalgaz (CNG) ve biyokütle gibi yenilenebilir enerji kaynaklarının dağıtımında kullanılan temiz enerjinin üretimini ve kullanımını içerir ve tüm bu enerji kaynakları, operasyonlarda daha yüksek enerji verimliliği sağlar,

- Yeşil ürün; Bu, yeşil ürün geliştirmenin ikinci adımıdır,

- Yeşil süreç: Bu yöntem, genellikle yalın işlemler yoluyla atık oluşumunun azaltılmasını içeren ticari faaliyetlerde kullanılır.

Yeşil üretimin temel amacı, üretim aşamasında atık miktarını dolaylı olarak azalttığ 1 için işlenmemiş malzemenin kullanımını azaltmaktır. Yeşil üretimin bir diğer önemli yönü "emisyon azaltımı" dır.

\section{Yeşil dağıtım}

İşletmeler, yeşil tedarik zinciri konusundaki stratejilerini belirlerken ürünlerin dağıtımı, enerji ve kaynak girdilerinin azaltılması şeklinde yapılarak yeşil değerlerini ortaya koyabilmektedir. Örnek olarak; az miktarda kaynak kullanılarak daha çok tüketiciye ulaşmak için lojistik maliyetlerinin minimize edilmesinde kullanılabilmektedir (Emgin ve Türk, 2004: 7). Diğer bir ifadeyle daha az karbon salınımı gerçekleştirmek için dağıtım kanallarının optimal şekilde planlanması ve çevreci yakıt sistemlerinin tercih edilmesi de yeşil dağıtımı için etkili bir yöntem olarak görülmektedir.

\section{Yeşil paketleme}

Yeşil paketlemeyi, ürünlerin paketlenmesi işleminde kullanılan malzemelerin geri dönüşüm işlemlerine uygun özelliklere sahip olması ve işlemin en az araç gereç ve en az alan kullanılmasıyla yapılması olarak ifade edilebilir (Sarkis, 2003: 399).

\section{Tersine lojistik}

Tersine lojistik, mamullerin ve/veya malzemelerin, geri kazanılması ya da uygun bir biçimde bertaraf edilmesi amacıyla, son kullanıcıdan diğer herhangi bir noktaya ulaştırılması sırasındaki bütün faaliyetleri kapsar (Alumur, 2013: 117118).

Üretim sektöründe tersine lojistik, nihai kullanıcıdan satıcıya ya da hizmet sağlayıcıya geri gelen mamullerin hareketi, depolanması ve elleçlenmesi faaliyetlerini içerir (Keskin, 2011: 35). Bu süreç, hasardan dolayı iade edilmiş 
ticari özellik taşıyan malları yeniden üretim işlemine dahil etmeyi, tekrar stoklamayı, hurdaları, ürün geri çağırmalarını ve yeniden paketlemeyi ve nihai kullanıcıya ürünlerin gönderimini içerir (Blanchard, 2017: 139).

Tersine lojistik faaliyetleri; Geri dönüşüm, yeniden üretim, yeniden kullanım ve bertaraf etme gibi alt faaliyetlerden oluşmaktadır.

Geri dönüşüm: Ömrünü tamamlamış ürünlerin veya ambalajlarının (metal, kağıt, cam ve plastik gibi) ayrıştırılarak tekrardan hammadde ya da yarı mamul olarak üretim süreçlerine katılmasıdır.

Yeniden üretim: Ömrünü tamamlamış ve yıpranmış ürünlerin bir takım endüstriyel işlemler sonrasında yeni bir mamul haline getirilmesidir (Aksoy, 2007: 122).

Yeniden kullanım: Ürünün tasarlandığı amaca benzer bir şekilde herhangi bir işleme alınmadan tekrar kullanılmasıdır (Alumur, 2013: 121).

Bertaraf etme: Geri dönüşümü mümkün olmayan ya da çok pahalı olan ürün ve ambalajların çevreye zarar vermeyecek şekilde yok edilmesidir.

\section{METODOLOJí}

$\mathrm{Bu}$ kısımda araştırmaya ait alan çalışmasının yapılmasına ilişkin bilgiler bulunmaktadır.

\section{Araştırmanın amacı ve kapsamı}

$\mathrm{Bu}$ çalışmanın amacı; Gaziantep’te çeşitli sektörlerde faaliyet gösteren işletmelerin çevreye duyarlılıklarını ve tersine lojistik faaliyetleri üzerindeki etkilerini ortaya koymaktır. Çalışmanın kapsamını ise Gaziantep Sanayi Odasına kayıtlı işletmeler oluşturmaktadır.

\section{Anakütle, örneklem ve geri dönüş oranı}

Araştırmanın ana kütlesini GSO (Gaziantep Sanayi Odas1)'na kayıtlı 2181 firma oluşturmaktadır (GSO, 2020). Araştırmanın örneklemi \% 95 güven seviyesinde ve $\% 5$ güven aralığında 327 olarak belirlenmiştir. Bu bağlamda örneklem sayısı olan 327 işletme içerisinde basit örnekleme yöntemi kullanılarak 112 işletmeye ulaşılmış ve anket formu uygulanmıştır. Çalışma sonucunda araştırmanın geri dönüş oranı \% 34,25 oranında gerçekleşmiştir.

\section{Araştırmanın prosedürü ve verilerin toplanması}

Çalışma için Hasan Kalyoncu Üniversitesi Sosyal ve Beşeri Bilimler Etik 
Kurulundan 14.10.2020 tarih ve E--804.01-BABBFCF3 sayıl1 etik kurul izni alınmıştır. Çalışmada kullanılan araştırma formu üç bölümden oluşmaktadır. İlk bölümde işletmelerin demografik özelliklerini ölçmeye yönelik sorular, ikinci bölümde işletmenin çevresel duyarlılığını ölçmeye yönelik sorular ve üçüncü bölümde ise işletmelerin tersine lojistik uygulamalarını ölçen sorulardan oluşmaktadır. Araştırmada kullanılan ölçekler, geçerliliği ve güvenirliliğgi ispatlanmış ölçeklerin geliştirilmesi ile elde edilmiştir. Bu değişkenleri ölçmek için, ankette (Zhu vd., 2008) tarafindan geliştirilen ölçekten yararlanılmıştır. Diğer yandan ankette $(\mathrm{Li}, 2011)$ tarafindan geliştirilen yeşil tedarik zinciri için kriterleri esas alınmıştır. Çevresel performans ölçeği ise, (French and LaForge, 2006)'ın geliştirdiği proses endüstrilerinde yeniden kullanım araştırma konularından yararlanılarak hazırlarlanmış ve (Korkankorkmaz, 2012)'nin çalışmasında kullanılmıştır ve bu ölçekler izin alınarak kullanılmıştır.

Çalışmanın ana değişkenleri olan çevresel duyarlılık sonuçları ve tersine lojistik faaliyetlerine ilişkin sorular 5'li likert ölçeğinden oluşmaktadır. Ayrıca ankette yer alan soruların doğru anlaşılıp anlaşılmadığını belirlemek için bir pilot çalışma yapılmıştır. Anketler, işletmelere online olarak ulaşılarak tamamlanmış ve 112 işletmeden olumlu yanıt alınmıştır.

\section{Araştırmanın kısıtları ve güvenilirliği}

Araştırma, Gaziantep ilinde Organize Sanayi Bölgesinde yer alan fabrikalar arasında görüşme talebine olumlu yanıt veren işletmelerin sayısı ve ankete verilen cevapların doğruluğu ile sinırlıdır.

\section{Araştırmanın hipotezi ve modeli}

İşletmelerin, çevresel duyarlılıklarının tersine lojistik uygulamalarına etkileri araştırılmaktadır.

Buna göre oluşturulan araştırma hipotezi şu şekildedir:

H1: İşletmelerin çevresel duyarlılıkları, tersine lojistik uygulamalarını pozitif etkilemektedir

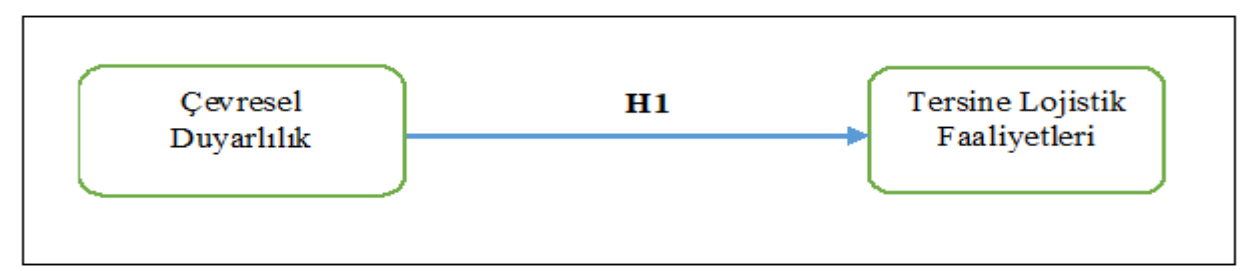

Şekil 3. Araştırmanın Modeli 


\section{ARAŞTIRMANIN BULGULARI}

Çalışmanın bu kısmında araştırma sonucundan elde edilen bulguların analizlerine ve yorumlarına yer verilmiştir.

\section{Geçerlilik ve güvenilirliğe ait bulgular}

Çalışma da ölçeklerin içsel tutarlılığının test edilmesinde de Cronbach alfa değeri kullanılmıştır. Yapılan güvenilirlik analizine ilişkin bulgular, çevresel duyarlılık bölümü alt ölçekleri olarak Tablo 1'de, Tersine lojistik faaliyetleri alt ölçekleri olarak ta Tablo 2'de sunulmuştur.

Ayrıca ölçeklerin geçerlilikleri (Korkankorkmaz, 2012) tarafından yapılmış ve ölçeklerin geçerli olduğu sonucuna varılmıştır $(\mathrm{KMO}=, 740 ; \mathrm{p} \leq 0,01)$.

Tablo 1. Çevresel Duyarlılık Ölçeğinin Maddelerle Toplam Korelasyonu Ve Alfa Değerleri

\begin{tabular}{|c|c|c|c|c|}
\hline & \multicolumn{4}{|c|}{ Madde çıkarıldığında toplam } \\
\hline Ölçek maddeleri & Ort. & Vary. & Kor. & Alfa \\
\hline $\begin{array}{l}\text { Üst yönetimin yeşil tedarik zinciri yönetimine ilişkin } \\
\text { taahhüdü bulunmaktadır }\end{array}$ & 125,41 & 1107,992 &, 713 & ,970 \\
\hline $\begin{array}{l}\text { Orta düzey yöneticilerin yeşil tedarik zinciri yönetimine } \\
\text { desteği bulunmaktadır }\end{array}$ & 125,28 & 1107,521 , & 775 & 970 \\
\hline $\begin{array}{l}\text { Çevresel konularda iyileştirmeler için departmanlar arası } \\
\text { iş birliği vardır }\end{array}$ & 125,31 & 1100,811, & 819 & ,969 \\
\hline Kalite kapsamında çevresel programlar uygulanmaktadır & 125,38 & 1096,777 & 859 & 969 \\
\hline Çevresel uyur & 125,47 & 1094,288, & 844 & 969 \\
\hline ISO 14001 belgesi bulunm & 125,38 & 1094,455, & 834 & 969 \\
\hline Cevre yönetim & 125,48 & 1093,928, & 842 & 969 \\
\hline $\begin{array}{l}\text { Çevresel koşullarımızı ve gerekliliklerimizi belirten } \\
\text { dizayn kriterleri tedarikçilerimize sağlanmaktadır }\end{array}$ & 125,15 & 1091,67 & 222 & 983, \\
\hline $\begin{array}{l}\text { Çevresel amaçları geliştirmek için tedarikçiler ile iş birliği } \\
\text { yapılmaktadır }\end{array}$ & $\mathbf{i} 125,49$ & 1101,333, & 826 & 969 \\
\hline $\begin{array}{l}\text { Tedarikçilerin, çevre yönetim sistemi düzenli olarak } \\
\text { denetlenmektedir }\end{array}$ & 125,54 & 1097,92 &, 784 & 969 \\
\hline Tedarikçilerin ISO 14001 belgelendirilmesi vardır & 125,43 & 1103,977, &, 778 & 970 \\
\hline $\begin{array}{l}\text { Tedarikçilerimizin tedarikçileri de çevreci uygulamalar } \\
\text { bakımından değerlendirilmektedir }\end{array}$ & 125,55 & 1094,285, & 8,846 & 969 \\
\hline lojik dizayn için iş birliği yapılmaktadır & 125,35 & 1114,265, & ,340 & 973 \\
\hline $\begin{array}{l}\text { Müşteriler ile daha temiz üretim için iş birliği } \\
\text { yapılmaktadır }\end{array}$ & 125,43 & 1104,46 & ,777 & 970, \\
\hline $\begin{array}{l}\text { Müşteriler ile ürün sevkiyatının çevreye daha duyarlı } \\
\text { gerçekleştirilmesi için iş birliği yapılmaktadır }\end{array}$ & 125,54 & 1097,34 &, 804 & ,969 \\
\hline $\begin{array}{l}\text { Müşteriler ile çevreye duyarlı paketleme için iş birliği } \\
\text { yapılmaktadır }\end{array}$ & 125,47 & 1096,17 & ,835 & 969, \\
\hline
\end{tabular}




\begin{tabular}{|c|c|c|c|c|}
\hline $\begin{array}{l}\text { Müssteriler ile enerji kullanımının azaltılması için iş birliği } \\
\text { yapılmaktadır }\end{array}$ & 125,45 & 1100,232 & ,792 & 969 \\
\hline Hurda ve kullanılmış malzemelerin satışı yapılmaktadır & 125,45 & 1104,466 & 730 & ,970 \\
\hline Fazla ekipmanların satışı yapılmaktadır & 125,50 & 1099,117 &, 755 & 970 \\
\hline $\begin{array}{l}\text { Ürünler enerji tüketimini azaltacak şekilde } \\
\text { tasarlanmaktadır }\end{array}$ & 125,36 & 1100,883 &, 818 & 969 \\
\hline $\begin{array}{l}\text { Ürünler malzeme tüketimini azaltacak şekilde } \\
\text { tasarlanmaktadır }\end{array}$ & 125,38 & 1101,534 & 808 & 969 \\
\hline $\begin{array}{l}\text { Ürünler tehlikeli maddeler kullanılmayacak şekilde } \\
\text { tasarlanmaktadır }\end{array}$ & 125,34 & 1100,767 & ,819 & 969 \\
\hline Ürünler geri dönüșüme uygun şekilde tasarlanmaktadır & 125,26 & 1102,630 & 835 & 969 \\
\hline Ürünler yeniden kullanıma uygun tasarlanmaktadır & 125,34 & 1100,100 & 834 & ,969 \\
\hline $\begin{array}{l}\text { Firma için çevreye duyarlılık, her şeyden önce etik bir } \\
\text { gerekliliktir. }\end{array}$ & 125,36 & 1097,712 & 832 & 969 \\
\hline $\begin{array}{l}\text { Geri dönüşüm ve yeniden kazanım faaliyetleri için etik bir } \\
\text { gerekliliktir }\end{array}$ & $\mathrm{r} \mid 125,31$ & 1102,181 & 836 & 969 \\
\hline $\begin{array}{l}\text { Üretim süreçlerinde çevreye zararlı maddelerin } \\
\text { kullanılması etik dışı bir yaklaşımdır }\end{array}$ & 125,25 & 1102,207 & 7,800 & 969 \\
\hline $\begin{array}{l}\text { Bir önceki yıla göre firmamız, üretim sürecinde tehlikeli } \\
\text { maddeleri azaltmıştır }\end{array}$ & 125,24 & 1100,635 & 5,840 & 969 \\
\hline $\begin{array}{l}\text { Bir önceki yıla göre firmamız, yeşil satın alma (çevreye } \\
\text { duyarlı) gerçekleştirmektedir }\end{array}$ & 125,27 & 1098,256 & 5,874 & 969 \\
\hline $\begin{array}{l}\text { Bir önceki yıla göre firmamız, yeşil tasarım } \\
\text { gerçekleştirmektedir }\end{array}$ & 125,29 & 1097,900 & ,852 & 969 \\
\hline $\begin{array}{l}\text { Bir önceki yıla göre firmamız, etkili bir Çevresel Risk } \\
\text { Yönetimi sistemi kurmuştur }\end{array}$ & 125,39 & 1096,529 & 8,827 & 969 \\
\hline $\begin{array}{l}\text { Bir önceki yıla göre firmamız, çalışanlarını çevresel } \\
\text { konularda bilinçlendirmiştir }\end{array}$ & 125,32 & 1097,103 & 3,818 & 969 \\
\hline $\begin{array}{l}\text { Bir önceki yıla göre firmamız, tüketicileri/müşterileri } \\
\text { çevresel konularda bilinçlendirmiştir }\end{array}$ & 125,30 & 1097,799 & 8,838 & 969 \\
\hline $\begin{array}{l}\text { Bir önceki yıla göre firmamız, daha iyi bir tersine lojisti } \\
\text { faaliyeti yürütmüştür }\end{array}$ & 125,36 & 1096,108 & 3,822 & 969, \\
\hline
\end{tabular}

Güvenirlilik katsayısı Cronbach alfa değeri: ,971

Tablo 2. Tersine Lojistik Ölçeğinin Maddelerle Toplam Korelasyonu Ve Alfa Değerleri

\begin{tabular}{|c|c|c|c|c|}
\hline & \multicolumn{4}{|c|}{ Madde cıkarıldığında toplam } \\
\hline Ölçek maddeleri & Ort. & Vary. & Kor. & Alfa \\
\hline İade mallar & 61,6429 & 434,916 & ,807 & ,980 \\
\hline Servis ve bakım için geriye alınan ürünler & 61,5982 & 434,765 &, 832 & 980 \\
\hline Parti/Sipariş fazlası ürünler & 61,5179 & 432,720 & ,848 & 980 \\
\hline Satıș şartnamesini karşılamayan ürünler & 61,4554 & 431,728 & ,862 & 980 \\
\hline Demode olmuş/eskimiş ürünler & 61,6875 & 426,631 &, 876 & 980 \\
\hline Raf ömrünü tamamlamış ürünler & 61,7054 & 426,462 & ,874 & 980 \\
\hline
\end{tabular}




\begin{tabular}{|l|l|l|l|}
\hline Stokta demode olmuş hammaddeler & 61,7143 & $427,413,882$ &, 980 \\
\hline Stokta raf ömrü geçmiş hammaddeler & 61,7054 & $424,408,919$ &, 979 \\
\hline İmha edilmesi gereken ürünler & 61,7946 & $424,183,889$ &, 980 \\
\hline Nakliye sırasında zarar gören ürünler & 61,6607 & $428,532,868$ &, 980 \\
\hline Ambalaj malzemeleri & 61,7946 & $430,363,816$ &, 980 \\
\hline Palet ve konteynırlar & 61,8036 & $430,934,773$ &, 981 \\
\hline Satılamayan ürünler & 61,7143 & $431,828,818$ &, 980 \\
\hline Tanıtılldı̆̆ı/söz verildiği gibi olmayan ürünler & 61,6071 & $428,349,862$ &, 980 \\
\hline Kirlenmiş ürünler & 61,4821 & $429,279,863$ &, 980 \\
\hline Numune ürünleri & 61,5893 & $431,379,834$ &, 980 \\
\hline Teşhir ürünleri & 61,6786 & $430,454,858$ &, 980 \\
\hline Yeniden kullanım için ürünler & 61,5536 & $429,529,876$ &, 980 \\
\hline
\end{tabular}

Güvenirlilik katsayısı Cronbach alfa değeri: ,981

Tablo 1 ve 2'de araştırmada kullanılan ana değişkenler ve bunların alt boyutları, madde sayıları ile alfa katsayıları görülmektedir. İşletmelerin Çevresel Duyarlılık uygulamalarının ölçeği Üst yönetim benimseme, ISO 14001 belgesi varlığı, Çevre Yönetim Sistemi, Tedarikçilerle ve Müşteriler ile çevre ile yapılan işbirlikleri vb. gibi alt ölçeklerinden oluşmaktadır. Tersine Lojistik Faaliyetleri sonuçları ölçeği ise iade mallar, parti fazlası ürünler, raf ömrü geçmiş, nakliye sırasında zarar gören, kirlenmiş, satılamayan ve teşhir ürünleri vb. gibi belirtilen ürünlerin alt ölçeklerinden oluşmaktadır. Tablo 1 ve 2'de görüldüğü üzere bütün ölçeklerin ve alt ölçeklerin alfa değerleri 0,70 'den büyüktür. Tablo incelendiğinde ölçeklerin içsel tutarlılığının yüksek olduğu görülmektedir. Ölçeklerin alfa değerleri 0,96 ile 0,98 aralığında değerler aldığı ve bu ölçeklerin güvenilir olduğunu, ölçülmek istenilen özelliğin doğru biçimde ölçüldüğünü göstermektedir. Ayrıca ölçeklerde herhangi bir negatiflik bulunmamakta bu da ölçeklerin birleri ile uyumunun pozitif yönde olduğunun kanıtını oluşturmaktadır.

\section{Tanımlayıcı İstatistik ve Normallik Varsayımının İncelenmesi}

$\mathrm{Bu}$ bölümde araştırmada kullanılan ölçekler ilgili tanımlayıcı istatistikler, gözlem değerleri, normal dağılım varsayımları incelenmiştir. Tablo 3 ve Tablo 4 ’te görülmüştür.

Tablo 3. Çevresel Duyarlılık Ölçeğine İlişkin Tanımlayıcı İstatistikler

\begin{tabular}{|l|c|c|c|c|}
\hline \multicolumn{1}{|c|}{ Çevresel Duyarlıık Alt Ölçekler } & N & Ort. & $\begin{array}{c}\text { Std. } \\
\text { Sap. }\end{array}$ & Var. \\
\hline $\begin{array}{l}\text { Üst yönetimin yeşil tedarik zinciri yönetimine ilişkin } \\
\text { taahhüdü bulunmaktadır }\end{array}$ & 112 & 3,768 & 2,104 & 1,441 \\
\hline
\end{tabular}




\begin{tabular}{|c|c|c|c|c|}
\hline $\begin{array}{l}\text { Orta düzey yöneticilerin yeşil tedarik zinciri } \\
\text { yönetimine desteği bulunmaktadır }\end{array}$ & 112 & 3,893 & 1,174 & 1,250 \\
\hline $\begin{array}{l}\text { Çevresel konularda iyileştirmeler için departmanlar } \\
\text { arası iş birliği vardır }\end{array}$ & 112 & 3,8661 & 1,242 & 1,396 \\
\hline $\begin{array}{l}\text { Kalite kapsamında çevresel programlar } \\
\text { uygulanmaktadır }\end{array}$ & 112 & 3,8036 & 1,266 & 1,439 \\
\hline $\begin{array}{l}\text { Cevresel uyum ve denetim programları } \\
\text { bulunmaktadır }\end{array}$ & 112 & 3,7054 & 1,231 & 1,597 \\
\hline ISO 14001 belgesi bulunmaktadır & 112 & 3,7946 & 1,244 & 1,624 \\
\hline Cevre yör & 112 & 3,6964 & 1,309 & 1,619 \\
\hline $\begin{array}{l}\text { Çevresel koşullarımızı ve gerekliliklerimizi belirten } \\
\text { dizayn kriterleri tedarikçilerimize sağlanmaktadır }\end{array}$ & 112 & 4,0268 & 1,181 & 1,6044 \\
\hline $\begin{array}{l}\text { Cevevresel amaçları geliştirmek için tedarikçiler ile iş } \\
\text { birliği yapılmaktadır }\end{array}$ & 112 & 3,6875 & 1,184 & 1,352 \\
\hline $\begin{array}{l}\text { Tedarikçilerin, çevre yönetim sistemi düzenli olarak } \\
\text { denetlenmektedir }\end{array}$ & 112 & 3,6339 & 1,182 & 1,658 \\
\hline Tedarikçilerin ISO 14001 belgelendirilmesi vardır & 112 & 3,7500 & 1,127 & 1,396 \\
\hline $\begin{array}{l}\text { Tedarikçilerimizin tedarikçileri de çevreci } \\
\text { uygulamalar bakımından değerlendirilmektedir }\end{array}$ & 112 & 3,6250 & 1,174 & 1,588 \\
\hline $\begin{array}{l}\text { Müsşteriler ile ekolojik dizayn içi } \\
\text { yapılmaktadır }\end{array}$ & 112 & 3,8304 & 1,219 & 4,430 \\
\hline $\begin{array}{l}\text { ile daha temiz üretim için iş birliği } \\
\text { dır }\end{array}$ & 112 & 3,7500 & 1,134 & 1,378 \\
\hline $\begin{array}{l}\text { le çevreye duyarlı paketleme için iş birliği } \\
\text { dır }\end{array}$ & 112 & 3,7054 & 1,183 & 1,543 \\
\hline $\begin{array}{l}\text { Müşteriler ile ürün sevkiyatının çevreye daha duyarlı } \\
\text { gerçekleştirilmesi için iş birliği yapılmaktadır }\end{array}$ & 112 & 3,6239 & 1,156 & 1,604 \\
\hline $\begin{array}{l}\text { Müssteriler ile enerji kullanımının azaltılması için iş } \\
\text { birliği yapılmaktadır }\end{array}$ & 112 & 3,7232 & 1,154 & 1,517 \\
\hline $\begin{array}{l}\text { Hurda ve kullanılmış malzemelerin satışı } \\
\text { yapılmaktadır }\end{array}$ & 112 & 3,7321 & 1,188 & 1,549 \\
\hline Fazla ekipmanların satışı yapılmaktadır & 112 & 3,6786 & 1,247 & 1,716 \\
\hline $\begin{array}{l}\text { Ürünler enerji tüketimini azaltacak şekilde } \\
\text { tasarlanmaktadır }\end{array}$ & 112 & 3,8125 & 1,251 & 1,397 \\
\hline $\begin{array}{l}\text { Ürünler malzeme tüketimini azaltacak şekilde } \\
\text { tasarlanmaktadır }\end{array}$ & 112 & 3,8036 & 1,209 & 1,403 \\
\hline $\begin{array}{l}\text { Ürünler tehlikeli maddeler kullanılmayacak şekilde } \\
\text { tasarlanmaktadır }\end{array}$ & 112 & 3,8393 & 1,263 & 1,397 \\
\hline $\begin{array}{l}\text { Ürünler geri dönüşüme uygun şekilde } \\
\text { tasarlanmaktadır }\end{array}$ & 112 & 3,9107 & 1,252 & 1,271 \\
\hline Ürünler yeniden kullanıma uygun tasarlanmaktadır & 112 & 3,8393 & 1,174 & 1,379 \\
\hline $\begin{array}{l}\text { Firma için çevreye duyarlılık, her şeyden önce etik bir } \\
\text { gerekliliktir. }\end{array}$ & 112 & 3,8125 & 1,219 & 1,487 \\
\hline Geri dönüşüm ve yeniden kazanım faaliyetleri için & 112 & 3,8661 & 1,134 & 1,288 \\
\hline
\end{tabular}




\begin{tabular}{|l|c|c|c|c|}
\hline $\begin{array}{l}\text { Üretim süreçlerinde çevreye zararlı maddelerin } \\
\text { kullanılması etik dı̈s bir yaklaşımdır }\end{array}$ & 112 & 3,9186 & 1,183 & 1,400 \\
\hline $\begin{array}{l}\text { Bir önceki ylla göre firmamız, üretim sürecinde } \\
\text { tehlikeli maddeleri azaltmıştır }\end{array}$ & 112 & 3,9375 & 1,156 & 1,338 \\
\hline $\begin{array}{l}\text { Bir önceki yıla göre firmamız, yeşil satın alma } \\
\text { (çevreye duyarlı) gerçekleştirmektedir }\end{array}$ & 112 & 3,9018 & 1,154 & 1,333 \\
\hline $\begin{array}{l}\text { Bir önceki yıla göre firmamız, yeşil tasarım } \\
\text { gerçekleştirmektedir }\end{array}$ & 112 & 3,8929 & 1,188 & 1,412 \\
\hline $\begin{array}{l}\text { Bir önceki yıla göre firmamız, etkili bir Çevresel Risk } \\
\text { Yönetimi sistemi kurmuştur }\end{array}$ & 112 & 3,7857 & 1,247 & 1,557 \\
\hline $\begin{array}{l}\text { Bir önceki yıla göre firmamız, çalışanlarını çevresel } \\
\text { konularda bilinçlendirmiştir }\end{array}$ & 112 & 3,8571 & 1,251 & 1,565 \\
\hline $\begin{array}{l}\text { Bir önceki yıla göre firmamız, tüketicileri/müşterileri } \\
\text { cevresel konularda bilinçlendirmiştir }\end{array}$ & 112 & 3,8750 & 1,209 & 1,462 \\
\hline $\begin{array}{l}\text { Bir önceki yıla göre firmamız, daha iyi bir tersine } \\
\text { lojistik faaliyeti yürütmüştür }\end{array}$ & 112 & 3,8125 & 1,263 & 1,595 \\
\hline
\end{tabular}

Yeşil tedarik zinciri uygulamalarının çevresel duyarlılığını ölçme performans sonuçları Tablo 3'te gösterilmiştir. YTZY uygulamalarının ana ölçek madde ortalamalarının birbirine çok yakın olduğu analiz edilmiştir. En yüksek ortalama değerleri çevresel koşul ve gerekliliklerin belirten dizayn kriterleri tedarikçilere de sağlanması $(4,02)$ ve en düşük ortalama değeri ise Tedarikçilerimizin tedarikçileri de çevreci uygulamalar bakımından değerlendirilmektedir $(3,62)$.

Tablo 4. Tersine Lojistik Faaliyetleri Ölçeğine İlişkin Tanımlayıcı İstatistikler

\begin{tabular}{|l|c|c|c|c|}
\hline \multicolumn{1}{|c|}{ Tersine Lojistik Faaliyetleri Alt Ölçekler } & N & Ort. & $\begin{array}{c}\text { Std. } \\
\text { Sap. }\end{array}$ & Vary. \\
\hline İade mallar & & & & \\
\hline Servis ve bakım için geriye alınan ürünler & 112 & 3,633 & 1,321 & 1,748 \\
\hline Parti/Sipariş fazlası ürünler & 112 & 3,758 & 1,323 & 1,752 \\
\hline Satış şartnamesini karşılamayan ürünler & 112 & 3,821 & 1,330 & 1,770 \\
\hline Demode olmuş/eskimişürünler & 112 & 3,589 & 1,449 & 2,100 \\
\hline Raf ömrünü tamamlamıs̆ ürünler & 112 & 3,571 & 1,456 & 2,121 \\
\hline Stokta demode olmuş hammaddeler & 112 & 3,562 & 1,419 & 2,014 \\
\hline Stokta raf ömrü geçmiş hammaddeler & 112 & 3,571 & 1,443 & 2,085 \\
\hline Imha edilmesi gereken ürünler & 112 & 3,482 & 1,494 & 2,234 \\
\hline Nakliye sırasında zarar gören ürünler & 112 & 3,616 & 1,409 & 1,986 \\
\hline Ambalaj malzemeleri & 112 & 3,482 & 1,439 & 2,072 \\
\hline Palet ve konteynırlar & 112 & 3,473 & 1,494 & 2,234 \\
\hline Satılamayan ürünler & 112 & 3,562 & 1,393 & 1,942 \\
\hline Tanıtılldı̆ğ/söz verildiği gibi olmayan ürünler & 112 & 3,669 & 1,423 & 2,025 \\
\hline
\end{tabular}




\begin{tabular}{|l|c|c|c|c|}
\hline Kirlenmiş ürünler & 112 & 3,794 & 1,395 & 1,948 \\
\hline Numune ürünleri & 112 & 3,687 & 1,382 & 1,910 \\
\hline Teşhir ürünleri & 112 & 3,598 & 1,371 & 1,882 \\
\hline Yeniden kullanım için ürünler & 112 & 3,723 & 1,370 & 1,878 \\
\hline
\end{tabular}

Tersine lojistik ölçme performans sonuçları Tablo 4'te gösterilmiştir. Tersine lojistik uygulamalarının ana ölçek madde ortalamalarının birbirine çok yakın olduğu analiz edilmiştir. En yüksek ortalama değerleri "satış şartnamesini karşılamayan ürünler" $(3,82)$ ve en düşük ortalama değeri ise "palet ve konteynırlar" $(3,47)$ almıştır.

Tablo 5. Ölçeklerin Güvenirlik Analizi

\begin{tabular}{|l|l|c|}
\hline \multicolumn{3}{|c|}{ Güvenirlik Analizi } \\
\hline Ölçekler & Cronbach's Alpha & Madde sayısı \\
\hline Çevresel duyarlılık ölçeği &, 971 & 34 \\
\hline Tersine lojistik ölçeği &, 981 & 18 \\
\hline
\end{tabular}

Tablo 5 incelendiğinde, Çevresel duyarlılığa ait ölçeğin Cronbach's Alpha değeri ,971 ve Tersine lojistik ölçeğinin Cronbach's Alpha değerinin ,981 olduğu görülmektedir. Bu durum (Kalaycı, 2010: 405)'a göre ölçeklerin yüksek derece güvenilir olduklarını göstermektedir.

\section{İşletmelere Ait Tanımlayıcı Bilgiler}

$\mathrm{Bu}$ bölümde çalışmaya katılan işletmelerin çalışan sayıları, faaliyet yılları, ticari unvanları, sektörleri ve sahip olduğu kalite belgeleri gibi bilgilere yer verilmiştir. Bu bilgiler Tablo 6 ve Tablo 7 'de sunulmuştur.

Tablo 6. Araştırmaya Katılan İşletmelerin Demografik Bulguları

\begin{tabular}{|l|l|l|l|l|l|l|l|l|}
\hline $\begin{array}{l}\text { Calışan } \\
\text { sayısı }\end{array}$ & $\boldsymbol{f}$ & $\%$ & $\begin{array}{l}\text { Ticari } \\
\text { unvanı }\end{array}$ & $\boldsymbol{f}$ & $\boldsymbol{\%}$ & $\begin{array}{l}\text { Faaliyet } \\
\text { yılları }\end{array}$ & $\boldsymbol{f}$ & $\%$ \\
\hline $\begin{array}{l}1-100 \\
\text { aras1 }\end{array}$ & 70 & 62,5 & A.Ş. & 29 & 25,9 & $\begin{array}{l}1 \text { yıl -5 yıl } \\
\text { aras1 }\end{array}$ & 19 & 17 \\
\hline $\begin{array}{l}101-300 \\
\text { aras1 }\end{array}$ & 22 & 19,6 & Ltd .Şti. & 59 & 52,7 & $\begin{array}{l}6 \text { yıl - 10 yıl } \\
\text { aras1 }\end{array}$ & 29 & 25,9 \\
\hline $\begin{array}{l}301-500 \\
\text { aras1 }\end{array}$ & 3 & 2,7 & Kol. Şti. & 2 & 1,8 & $\begin{array}{l}11 \text { yıl - 15 } \\
\text { yıl arası }\end{array}$ & 27 & 24,1 \\
\hline $\begin{array}{l}501-1000 \\
\text { aras1 }\end{array}$ & 4 & 3,6 & Holding & 12 & 10,7 & $\begin{array}{l}16 \text { yıl - 20 } \\
\text { yıl arası }\end{array}$ & 11 & 9,8 \\
\hline
\end{tabular}




\begin{tabular}{|l|l|l|l|l|l|l|l|l|}
\hline $\begin{array}{l}1001 \text { ve } \\
\text { üstü }\end{array}$ & 13 & 11,6 & Diğer & 10 & 8,9 & $\begin{array}{l}21 \text { yll ve } \\
\text { üzeri faaliyet } \\
\text { gösteren }\end{array}$ & 26 & 23,2 \\
\hline Toplam & $\mathbf{1 1 2}$ & $\mathbf{1 0 0}$ & Toplam & $\mathbf{1 1 2}$ & $\mathbf{1 0 0}$ & Toplam & $\mathbf{1 1 2}$ & $\mathbf{1 0 0}$ \\
\hline
\end{tabular}

İşletmeler faaliyet yılları açısından incelendiğinde, işletmelerin \%92'sinin 300 ve altı sayıda çalışana sahip olduğu, \%59'unun limited şirket olduğu ve \%55'inin 10 yıldan daha uzun süredir faaliyette olduğu görülmektedir.

Tablo 7. Araştırmaya Katılan İşletmelerin Sektör ve Kalite Belgesi Sahipliğine Dair Bulgular

\begin{tabular}{|c|c|c|c|c|c|}
\hline $\begin{array}{l}\text { İşletmelerin faaliyette } \\
\text { bulunduğu sektörler }\end{array}$ & $f$ & $\%$ & $\begin{array}{l}\text { Ulusal kalite belgesi } \\
\text { sahipliği }\end{array}$ & $f$ & $\%$ \\
\hline Tekstil & 28 & 25,0 & Sahip olmayan & 5 & 4,5 \\
\hline Gida & 26 & 23,2 & $1-3$ aras1 & 85 & 75,8 \\
\hline $\begin{array}{l}\text { Dayanıklı Tüketim } \\
\text { Malları }\end{array}$ & 11 & 9,8 & 4- 7 aras 1 & 18 & 15,2 \\
\hline Otomotiv & 3 & 2,7 & 8 ve daha fazla & 5 & 4,5 \\
\hline Enerji & 1 & 9 & Toplam & 112 & 100 \\
\hline Bilişim & 1 & 9 & & & \\
\hline Sağlık-İlaç & 5 & 4,5 & $\begin{array}{l}\text { Uluslararası kalite } \\
\text { belgesi sahipliği }\end{array}$ & $f$ & $\%$ \\
\hline İnşaat & 5 & 4,5 & Sahip olmayan & 41 & 36,6 \\
\hline Taşımacılık ve Lojistik & 3 & 2,7 & $1-3$ aras 1 & 51 & 45,5 \\
\hline Petrokimya & 2 & 1,8 & 4- 7 aras1 & 18 & 16 \\
\hline Madencilik & 1 & 9 & 8 ve daha fazla & 2 & 1,8 \\
\hline Kağıt ve Ambalaj & 8 & 7,1 & Toplam & 112 & 100 \\
\hline Hizmet & 7 & 6,3 & & & \\
\hline Basın Yayın & 5 & 4,5 & & & \\
\hline Diğer & 6 & 5,4 & & & \\
\hline Toplam & 112 & 100 & & & \\
\hline
\end{tabular}

Tablo 7 incelendiğinde, araştırmaya katılan işletmelerin çoğunlukla Tekstil, Gıda ve Dayanıklı tüketim malları sektörlerinde faaliyette bulundukları görülmektedir. İşletmelerin kalite belge sayıları incelendiğinde büyük bir kısmının hem ulusal hem de uluslararası kalite belgelerine sahip olduğu görülmektedir.

\section{Korelasyon analizine ilişkin bulgular}

Araştırmada işletmelerin çevresel duyarlılığı önemseme dereceleri, tersine 
lojistik faaliyetleri sonuçları ilişkilerin tespit edilmesinde korelasyon analizi kullanılmıştır. Tablo 8 incelendiğinde çevresel duyarlılık ve tersine lojistik uygulamaları arasında istatistiki olarak anlamlı olan pozitif yönlü güçlü bir ilişki oluğu görülmektedir $(\mathrm{r}=, 793 ; \mathrm{p} \leq 0.01)$.

Tablo 8. Ölçekler Arasındaki Korelasyon

\begin{tabular}{|l|c|c|}
\hline Korelasyon analizi & CD & TLF \\
\hline CD & 1 & \\
\hline TLF &, $793^{*}$ & 1 \\
\hline
\end{tabular}

Çevresel duyarlılık (CD), Tersine lojistik faaliyetleri (TLF) *.p $\leq 0.01$

\section{Regresyon analizine ilişkin bulgular}

Çevresel duyarlılık ve tersine lojistik faaliyetleri ölçeklerinin ortalamaları alınarak regresyon analizi yapılmıştır. Analizde çevresel duyarlılık bağımsız değişken, tersine lojistik ise bağımlı değişken olarak analize alınmıştır.

Tablo 9. Regresyon analizine ait bulgular

\begin{tabular}{|l|l|c|l|l|l|l|}
\hline $\begin{array}{l}\text { Bağımsız } \\
\text { Değişken }\end{array}$ & $\boldsymbol{\beta}$ & $\mathbf{T}$ & $\mathbf{p}$ & $\mathbf{R}^{2}$ & Düzeltilmiş R & $\mathbf{F}$ \\
\hline $\begin{array}{l}\text { Çevresel } \\
\text { duyarlılık }\end{array}$ &, 793 & 13,674 &, $000^{*}$ &, 630 &, 626 & 186,99 \\
\hline
\end{tabular}

Bağımlı değişken: Tersine Lojistik Faaliyetleri (TLF) *:p $\leq, 001$

Tablo 9 incelendiğinde, bağımsız değişken durumundaki çevresel duyarlılığın, bağımlı değişken durumundaki tersine lojistik değişkenine ait varyansı \% 63 oranında açıkladığı görülmektedir $\left(\mathrm{R}^{2}=, 630 ; \mathrm{p} \leq, 001\right)$.

Tablo 10. Tek Yönlü ANOVA Analiz Tablosu

\begin{tabular}{|l|l|l|l|l|c|}
\hline Model & $\begin{array}{c}\text { Kareler } \\
\text { Toplamı }\end{array}$ & $\begin{array}{c}\text { Serbestlik } \\
\text { derecesi }\end{array}$ & $\begin{array}{c}\text { Ortalama } \\
\text { Kareler }\end{array}$ & F & Sig. \\
\hline Regresyon & 70,518 & 1 & 70,518 & 186,990 &, 000 \\
\hline Artıklar & 41,484 & 110 &, 377 & & \\
\hline Toplam & 112,002 & 111 & & & \\
\hline
\end{tabular}

Tablo 10' da ANOVA tablosu incelendiğinde, ANOVA analizi ile değişkenlerin arasından fark olup olmadığ 1 ile ilgili hipotez test edilmeye çalışılmıştır. $F=$ 186,990 ve Sig.= ,000 sonucuna göre $\% 95$ güven seviyesinde, tersine lojistik faaliyetlerini, çevresel duyarlılık ile açıklamaya çalışılan hipotez anlamlı bir şekilde açıklanabilmektedir. 
Tablo 11. Regresyon Modeli Katsayı Değerleri

\begin{tabular}{|l|l|l|l|l|}
\hline Model & \multicolumn{2}{|l|}{ Standartlaştırılmamı katsayılar } & & \\
\hline & B & Std. Hata & t & Sig. \\
\hline Sabit & 1,427 &, 183 & 7,804 &, 000 \\
\hline Çevresel Duyarlılık &, 654 &, 048 & 13,674 &, 000 \\
\hline
\end{tabular}

Bağımlı değişken: Tersine Lojistik Faaliyetleri, *: $\mathrm{p} \leq 0.001$

Tablo 11 incelendiğinde, parametrelerin anlamlılığını test etmek için t istatistiği değerleri de verilmiştir. Regresyon modelinin katsayısının değeri 1,427 olarak bulunmuştur ve \%14 seviyesinde anlamlılığa sahiptir $($ sig. $=, 000)$. Çevresel duyarlılık değerlerindeki 1 birimlik artış tersine lojistik faaliyetlerinde 0,654 birim arttıracaktır. Bu katsayıya ilişkin $t$ istatistiği değeri ve bunun significance değeri 0,000 çıkmıştır. Yani \%1 anlamlılık seviyesinde anlamlıdır.

Tablolar incelendiğinde, araştırmanın hipotezi olan "H1: İşletmelerin çevresel duyarlılıkları, tersine lojistik uygulamalarını pozitif etkilemektedir.", hipotezi kabul edilmiştir.

Yapılan regresyon analizi sonucunda $Y=b X+a$ (Büyüköztürk, 2016: 92) formülüyle kurulan denklem aşağıdaki gibidir.

$$
\text { Ý }=, 654 \mathrm{X}+1,427 \text { diğer deyişle }, \quad \mathrm{TLF}=, 654 \mathrm{CD}+1,427
$$

\section{SONUC}

Yeryüzünde doğal kaynakların sürekli azalması ya da tükenmesi sonucunda katılaşan çevresel yasalar ve giderek artan rekabet koşulları, işletmelerin faaliyetlerini daha çevreci yapmaları konusunu sürekli olarak gündem de tutmaya devam etmektedir.

(Chen vd., 2019), çalışmalarında yeşil tedarik zinciri uygulamalarının çevreye verilen zararın en aza indirgenmeyi amaçladığını ifade etmişlerdir.

Şüphesiz günümüzde çevreci olarak faaliyetleri sürdürmenin en popüler yolu yeşil tedarik zinciri faaliyetleridir. Yeşil tedarik zincirinin en önemli amacı, işletmelerin esas faaliyetlerini sürdürürken çevreye olan zararları en aza indirmektir. Tam anlamıyla kullanılabilen; yeşil satın alma, yeşil üretim, yeşil dağıtım, yeşil paketleme ve tersine lojistik gibi yeşil tedarik zinciri faaliyetleri işletmeler için çok büyük avantajlar sağlamaktadır.

Sadece ilk yatırım maliyeti içeren bu uygulamalar orta ve uzun vadede işletmelere önemli maliyet avantajları sağlamakla kalmayıp, aynı zamanda oluşturduğu olumlu imaj sayesinde de tüketicilerin sempatisini kazanmaktadırlar. $\mathrm{Bu}$ da beraberinde işletmelere rekabet avantaj1 getirmektedir. 
İşletmelerin önemli bir çevre bilincine sahip olmaları ve yeşil tedarik zinciri uygulamalarından biri olan tersine lojistik uygulamalarını kullanıyor olmaları işletmelere önemli bir kaynak tasarrufu sağlamaktadır.

Bu doğrultuda bu çalışmada Gaziantep'te faaliyet gösteren işletmelerin tersine lojistik uygulamalarını kullanıp kullanmadıkları ve çevresel bir duyarlılığa sahip olup olmadıkları belirlenmeye çalışılmıştır. Çalışmanın sonucunda Gaziantep'te faaliyette bulunan işletmelerin hem çevresel duyarlılığa sahip oldukları hem de tersine lojistik uygulamalarını kullandıkları sonucuna ulaşıımıştır. Çalışma, görüşme talebine olumlu yanıt veren firmaların sayısı ve cevapların doğruluğu ile sınırlı kalmıştır.

$\mathrm{Bu}$ çalı̧̧mada elde edilen sonuçlara göre; araştırmanın hipotezi olan "H1: İşletmelerin çevresel duyarlılıkları, tersine lojistik uygulamalarını pozitif etkilemektedir.” hipotezi kabul edilmiştir. Bu sonuçla, Gaziantep 'te faaliyet gösteren işletmelerin hem tersine lojistik uygulamaları hem de çevre bilinci konusunda farkındalığa sahip oldukları sonucuna ulaşılabilir.

Günümüz işletmelerinde olduğu gibi gelecekte de çevre bilincine sahip olarak yeşil tedarik zinciri uygulamalarını kullanan işletmeler önemli rekabet güçlerine sahip olacaklardır.

Bunların yanısıra yeşil tedarik zincirin esnekliği ve çevikliği de işletmelerin rekabet güçlerini artıracak önemli konulardan biridir (Yıldız ve Çetindaş, 2020).

Son olarak endüstri de tedarik zinciri üzerinde yer alan bütün iş ortaklarının yeşil tedarik zinciri uygulamalarını doğru ve etkin bir şekilde kullanımı çevreye verilen negatif etkileri ortadan kaldıracaktır. Özellikle tedarik zinciri ve lojistiğin çevresel etkilerinden dolayı gelecek te yeşil tedarik zinciri ile ilgili çalışmalar güncelliğini korumaya devam edecektir.

\section{KAYNAKÇA}

Akben, İ. ve Demirer, Y. (2020). Yeşil ve Tersine Lojistikte Geri Dönüşüm Davranışı, Geri Dönüşümde Tüketicinin Rolü, İdeal Kültür Yayıncılık.

Aksoy, H. K. (2007). Yeniden üretim sistemlerinde en iyi geri dönüşüm ve atık politikalarının belirlenmesi, Eskişehir Osmangazi Üniversitesi Mühendislik ve Mimarlık Fakültesi Dergisi, 20(2), 121-134.

Alumur, S. (2013). Tersine lojistik. İçinde B.Y. Kara ve A. Taşer (Ed.) Çağdaş Lojistik Uygulamaları, (ss.116-128), Anadolu Üniversitesi, Açıöğretim Fakültesi Yayınları. 
Beamon, B. M. (1999). Designing the green supply cahin, Logistics Information Management, 12(4), 332-342. https//doi.org/10.1108/09576059910284159

Blanchard, D. (2017). Tedarik zinciri yönetimi, en iyi uygulamalar, (Çev. Mehmet Tanyaş ve Murat Düzgün), Nobel Yayınevi.

Bowersox, D. Closs, D. and Cooper, M.B. (2002). Supply chain logistics management, McGraw-Hill / Irwin, New York

Büyüközkan, G. ve Vardaloğlu, Z. (2008). Yeşil tedarik zinciri yönetimi, Lojistik Dergisi, 8, 66-73.

Büyüköztürk, Ş. (2016). Sosyal bilimler için veri analizi el kitabl, istatistik, araştırma deseni SPSS uygulamaları, 22. Baskı, Pegem Akademi

Chen, D. Ignatius, J. Sun, D. Zhan, S. Zhou, C. Marra, M. and Demirbag, M. (2019). Reverse logistics pricing strategy for a green supply chain: a view of customers' environmental awareness, International Journal of Production Economics, 217, 197-210.

CSCMP (Council of Supply Chain Management Professionals), (2008). http://cscmp.org/

Emgin, Ö. ve Türk, Z. (2004). Yeşil pazarlama (Green marketing), Mevzuat dergisi, 7(78).

French, M. L. and LaForge, R. L. (2006). Closed-loop supply chains in process industries: an empirical study of producer re-use issues, Journal of Operations Management, No.24. 271-286.

Gaziantep Sanayi Odası Üye Listesi, https://gso.org.tr/tr/uye-firmalar.html, (15.01.2020).

Güzel, D. ve Demirdöğen, O. (2015). Yeşil tedarik zinciri yönetimi, The International New Issues in Social Sciences, 1(1), 45-70.

Hart, T. Capps, A. D. and Bauer, M. (2010). Non profit guide to going green, John Wiley \& Sons, New Jersey.

Kalaycı, Ş. (2010). SPSS uygulamalı çok değişkenli istatistik teknikleri, Asil Yayın Dağıtım. 
Kaur, H. Singh, C. D. ve Singh, R. (2018). Achieving excellence through green supply chain management in manufacturing industries, BookRix Publications.

Keskin, M. H. (2011). Lojistik, tedarik zinciri yönetimi, Nobel Yayın.

Koca, G. ve Behdioğlu, S. (2019). Yeşil tedarik zinciri yönetiminde çok kriterli karar verme: otomotiv ana sanayi örneği, Eskişehir Osmangazi Üniversitesi Iktisadi ve İdari Bilimler Dergisi, 14, (3) , 675-698. https://doi.org/10.17153/oguiibf.491356

Korkankorkmaz, N. (2012). Yalın ve yeşil tedarik zinciri yönetimine iliş̧in bir araştırma, [Yüksek lisans tezi]. Gebze Yüksek Teknoloji Enstitüsü.

Lee, H. L. ve Billington, C. (1992). Managing supply chain inventory: pitfalls and opportunities, MIT Sloan Management Review, 33(3), 65-73.

Li, Y. (2011). Research on the performance measurement of green supply chain management in china, Journal of Sustainable Development, 4(3), https://doi.org/101-107.10.5539/jsd.v4n3p101

Sarkis, J. (2001). Manufacturing's role in corporate environmental sustainability concerns fort he new millennium, International Journal of Operations \& Production Management, 21, (5/6), 666-686. https://doi.org/10.1108/01443570110390390

Sarkis, J. (2003). A strategic decision framework for green supply chain management, Journal of Cleaner Production, 11, (4), 397-409. https://doi.org/10.1016/S0959-6526(02)00062-8

Sarkis, J. and Dou, Y. (2018). Green supply chain management, a concise introduction, Routledge Taylor \& Francis, U.K.

Sarkis, J. Zhu, Q. and Lai, K. (2011). An organizational theoretic review of green supply chain management literature, International Journal of Production Economics. 130(1), 1-15. https://doi.org/10.1016/j.ijpe.2010.11.010

Srivastava, S. K. (2007). Green supply-chain management: a state-of-the-art literature review, International Journal of Management Reviews, 9, 53-80. http://dx.doi.org/10.1111/j.1468-2370.2007.00202.x

Yarlıkaş, S. ve Can, Z.V. (2019). Yeşil tedarik zinciri yönetimini etkileyen faktörlerin önem siralamalarının swara ve copeland yöntemleri ile belirlenmesi, Eskişehir Osmangazi Üniversitesi İktisadi ve İdari Bilimler Dergisi, 14(3), 899-924. https://doi.org/10.17153/oguiibf.519150 
Yıldız, B. ve Çetindaş, A. (2020). Tedarik zinciri entegrasyonunun firma performansı üzerindeki etkisinde tedarik zinciri esnekliği ve tedarik zinciri çevikliğinin aracı rolü, Verimlilik Dergisi, 3, 175-199.

Zhu, Q. Sarkis, J. and Lai, K. (2008). Confirmation of a mesarument model for green supply chain management practices implementation, International Journal of Production Economics, 111(2), 261-273. https://doi.org/10.1016/j.ijpe.2006.11.029

Zhu, Q. Sarkis, J. and Lai, K. (2008). Green supply chain management implications for 'closing the loop, Transportaion Research Part E44, 1-18. https://doi.org/10.1016/j.tre.2006.06.003 